\title{
A COUNTRY SCENARIOES OF FOOD SECURITY AND GOVERNANCE IN BANGLADESH
}

\author{
M A Kashem ${ }^{1}$ and M A A Faroque ${ }^{2}$
}

\begin{abstract}
The Government of Bangladesh has identified food security as an important factor contributing to its socio-economic stabilization and development. Bangladesh has made a steady progress in the expansion of food production. But because of the increasing population pressure there has been an extensive use of land to meet the growing demand for food. Despite the growth in food production and its availability, food insecurity is still a major problem mainly because of the lack of purchasing power and thus of access to food, especially for the ultra poor community. This paper focuses on the availability of food as an essential element of the concept of food security and role of government to get food sufficiency. In addition to rice and wheat that constitute the staple food of Bangladesh, the paper deals with the production and availability issues of other major food commodities, such as potato, pulses, oilseeds, vegetables and fruits, and fisheries and livestock products. The food production of the country both rice and wheat, was 10.46 million metric tons in the 1971-72. Bangladesh attained self sufficiency in food production in 2010-2011 with a gross production of rice and wheat of 35.3 million metric tons which marginally met the country's requirement of 23.64 million metric tones for the population of 148.69 million, taking 453.6 g per capita per day requirement. Production of vegetables and fruits has increased, from 1.5 million tons and 1.46 million tons in 2001-02 to 7.19 million tons and 3.56 million tons in 2009-10 respectively. Fish production increase from 2.0 million tons in 2001-02 to 3.0 million tons in 2010-11. Livestock product (meat, milk and egg) has also increase $50 \%$ over that last ten years. Of these, domestic production is critical in ensuring food availability at both national and household levels. Government of Bangladesh is trying to integrate and address all the elements associated with food security to achieve touch the MDG setting for the country. However, in recent years, the Government is putting additional efforts to increase production of important food crops as well as fisheries and livestock.
\end{abstract}

Keywords: Food, Security, Governance, Bangladesh

\section{INTRODUCTION}

The understanding of people of Bangladesh stands food security means a stock of cereals that can be used to meet an unforeseen food crisis. Food certainly is not cereal alone, neither its security is just a sufficient amount of cereal stock. Food means balanced diet and its security refers to availability of such diet at a reasonable price. Ensuring food security for all is one of the major challenges that Bangladesh faces today. Despite significant achievement in food grain production and food availability, food security at national, household and individual levels remains a matter of major concern for the Government mainly due to natural calamities. Since independence, Bangladesh has

1 Director, TTMU, BARC and Director, Project Implementation Unit, National Agricultural Technology Project, Bangladesh Agricultural Research Council, Farmgate, Dhaka, Bangladesh.

2 Personal Secretary, Project Implementation Unit, National Agricultural Technology Project, Bangladesh Agricultural Research Council, Farmgate, Dhaka, Bangladesh. 
made substantial progress in increasing domestic production of food grains. The food production of the country both rice and wheat, was 10.46 million metric tons in the year 1971-72. Bangladesh attained self-sufficiency in food production in 2010-2011 with a gross production of rice and wheat of 35.0 million metric tons (BER, 2011) which marginally met the country's requirement of 24.62 millions metric tons for the population of 148.69 million, taking 453.6 gm per capita per day requirement. Food availability is one of the three conditions of food security as defined in the World Food Summit 1996. The other two conditions are access and utilization. This paper focuses firstly on the availability of food as an essential element of the concept of food security and secondly role of government to achieve food self-sufficiency.

\section{FOOD SECURITY STATUS}

Food security situation in Bangladesh has improved, especially on average per capita dietary energy supply has improved from $1800 \mathrm{Kcal}$ in 70s to 3055 in 2009 (BBS 2010), and further improvements on access and utilization, to be sustainable and large-scale, needs renewed efforts from the government, civil society (including media) and the development partners.

Records say in 70s', 70\% people were under the food consumption poverty line. Today this is down and $35 \%$ of the population under food consumption poverty line.

It has been evident that increased domestic production, supplemented by imports and overall public food management contributed to relatively adequate availability of food at national level over the recent past years. However, as has been mentioned, the fundamental spirit of food security is to ensure availability and consumption of food at individual level. Even when aggregate food supplies are adequate, a number of factors may prevent households or individuals from acquiring enough food. The overall productivity of the poor producers may be low or their income levels may be insufficient to enable them to purchase the necessary foods from the market at the ruling prices. Households may also lack the necessary asset or access to credit to overcome the period of hardship. They may also remain outside the food assistance programmes that would provide them with cash or kind income to supplement their food acquisition capacity.

Food security at household level is closely linked with poverty. These poverty and food security problems are massive, with approximately half of the population lacking the resources to acquire enough food and consequently remaining below the poverty line. Two approaches are generally used for measuring the incidence of poverty: direct calorie intake (DCI) method and cost of basic need (CBN) method. The Bangladesh Bureau of Statistics (BBS) has estimated the extent of poverty using the DCI method through its successive Household Expenditure Surveys (HES). In addition, the CBN method of estimation has also been introduced in the household expenditure surveys.

Table1: Poverty situation in Bangladesh as measured by the cost of basic need (CBN) method

\begin{tabular}{|l|l|l|l|l|l|l|}
\hline \multirow{2}{*}{ Location } & \multicolumn{5}{|c|}{ Percent of population below poverty line } \\
\cline { 2 - 7 } & \multicolumn{4}{|c|}{ Upper poverty line } & \multicolumn{3}{c|}{ Lower poverty line } \\
\cline { 2 - 7 } & $\mathbf{1 9 9 1}$ & $\mathbf{2 0 0 0}$ & $\mathbf{2 0 1 0}$ & $\mathbf{1 9 9 1}$ & $\mathbf{2 0 0 0}$ & $\mathbf{2 0 1 0}$ \\
\hline National & 58.80 & 48.90 & 31.50 & 42.70 & 33.70 & 17.60 \\
\hline Rural & 61.20 & 52.30 & 35.02 & 46.00 & 37.40 & 21.10 \\
\hline Urban & 44.90 & 35.30 & 21.30 & 23.30 & 19.10 & 07.70 \\
\hline
\end{tabular}


Today, though people are not dying, they are going hungry and becoming stunted with reduced mental and physical capacity. They are suffering. The hungry population of over 60 million people is larger than most other global cases- the third largest poor population in any country after China and India (UNDP, 2005). Nearly half of Bangladesh's children are underweight, making it one of the most severe cases of malnutrition in the world. While Bangladesh has definitely got more food than it had thirty years back, yet almost nearly half of Bangladesh is still far from being food secure.

The World Bank and GoB-UN in their respective reports on MDGs put the target of 34\% children being underweight as non-attainable at present rates of progress. Much will need to be done to achieve the 2015 MDG target of halving the proportion of people who suffer from hunger and malnutrition. Demographic changes in upcoming years are likely to affect poverty and hunger in adverse ways.

While poverty is an overall denominator of this food insecurity in the country, the additional intensifiers are disability (gender, age, and physical challenge) and location (disaster proneness, access to the market, etc) as well as other aspects related to utilization (education, awareness, cultural practices, etc). Issues of governance and accountability further prevent attempts at providing targeted safety nets and price stabilization.

\section{Domestic production:}

Food grain production, particularly rice production has tripled in the last 40 years with the use of Green Revolution technology (high yielding varieties, fertilizers, irrigation and pesticide) coupled with growth of institutional infrastructure and a positive shift in public policy and market forces. As a major staple, rice occupies 77 percent of the gross cropped area and accounts for over 95 percent of food grain production (BARC, 2011). It provides about $75 \%$ of the calorie and 55\% of the protein in the average daily diet of the people (Hossain et al, 2004). Rice thus occupies the centre stage of food security and continues to draw major attention of the Government for further increasing the production.

Rice production continues to increase, but wheat production is showing a declining trend in recent years. Remarkable progress has been made in rice production during the last ten years.

In 2001-02, rice production was 24.30 million tons, which has steadily increased to 33.54 million tons in 2010-11 (Table 2). Wheat production also decreased from 1.6 million tons in 2001-02 to 0.97 million tons in 2010-11. Similarly, pulses and oilseed production steadily declined mainly because of the loss of areas under these crops to Boro rice and other remunerative winter crops. Production of vegetables and fruits has increased, but at a slow pace from 1.59 million tons and 1.47 million tons in 2001-02 to 11.19 million tons and 3.56 million tons in 2010-11 respectively. Spectacular success has been achieved in the production of potato. It has made a quantum jump from 2.90 million tons in 2001-02 to 8.30 million tons in 2010-1 (Table 2). Production of non-cereals such as pulses, oilseeds, vegetables and fruits, which are the chief sources of protein, mineral and vitamin, still remains far below the actual requirements, making it difficult to provide balanced diet for all.

Table 2: Domestic production (gross) trend of food grains, potato, pulses, oilseeds, vegetables and fruits (2001-02 to 2010-11)

(Million MT)

\begin{tabular}{|l|l|l|l|l|l|l|l|}
\hline \multirow{2}{*}{ Years } & \multicolumn{2}{|l|}{ Food grain } & Potato & Pulses & Oilseeds & Vegetables & Fruits \\
\cline { 2 - 6 } & Rice & Wheat & & & & & \\
\hline $2001-02$ & 24.30 & 1.61 & 2.90 & 0.35 & 0.39 & 1.59 & 1.47 \\
\hline $2010-11$ & 33.54 & 0.97 & 8.30 & 0.72 & 0.84 & 11.19 & 3.56 \\
\hline
\end{tabular}


Fish production increased from 1.89 million tons in 2001-02 to 2.89 million tons in 2010-11 (Table 3). Meat, milk and egg production has also increased significantly over the last ten years (Table 3). But the shortage is still present.

Table 3: Fish, meat, milk and egg production trend (1994-2005)

\begin{tabular}{|l|l|l|l|l|}
\hline Year & Fish (MnT) & Meat (MnT) & Milk (MnT) & Egg (Million) \\
\hline $2001-02$ & 1.89 & 0.78 & 1.78 & 4424 \\
\hline $2010-11$ & 2.89 & 2.95 & 1.98 & 6078 \\
\hline
\end{tabular}

DLS, DoF 2011

\section{Growth}

Crop sub-sector growth has been highly unstable varying from 5.23\% in 2005-06 to 4.82\% (estimated) in 2010-11(Bangladesh Economic Review, 2011). This shows that it is possible to enhance growth of crop agriculture with appropriate use of production inputs under favourable climatic conditions. On the other hand, growth instability in certain years indicates that crop agriculture is highly vulnerable to natural disasters and unpredictable climate behaviour. Growth of crop agriculture also depends on input availability, input quality and input-out price. Growth potential is high in livestock sub-sector. According to partial figures from the Bangladesh Economic Review, 2011 the livestock growth rate in 2010-11 was 3.54\% and 5.44\% for fisheries sub-sector. Bangladesh Economic Review 2011 also reports steady growth of livestock compared to crops, fisheries and forestry.

\section{Per capita availability:}

In estimating the per capita availability of food items, BARC based its calculation on the population size of 119, 130 and 148.69 million for the year 1994-95, 2004-05 and 2010-11 respectively and the per capita food intake figure published by BBS in 2010 (Household Income and Expenditure Survey, 2010). Accordingly, per capita availability of cereals (rice and wheat) has been found to increase from $374 \mathrm{~g} /$ day in 1994-95 to $647 \mathrm{~g}$ /day in 2010-11 (Table 4). Sharp increase in per capita availability of potato and vegetables is seen in the last four years, while the per capita availability of pulses and oilseeds has remained stagnant or declined. Availability of meat, milk and egg has also increased as shown in Table 4. Per capita fish availability increased from $27 \mathrm{~g}$ in 1994-95 to $56 \mathrm{~g}$ in 2010-11.

Table 4: Production and availability of major food items (1994-2011)

\begin{tabular}{|l|l|l|l|l|l|l|}
\hline \multirow{2}{*}{ Food Items } & \multicolumn{3}{|c|}{ Production (million tons) } & \multicolumn{3}{c|}{ Availability (gm/capita/day) } \\
\cline { 2 - 7 } & $\mathbf{1 9 9 4 - 9 5}$ & $\mathbf{2 0 0 4 - 0 5}$ & $\mathbf{2 0 1 0 - 1 1}$ & $\mathbf{1 9 9 4 - 9 5}$ & $\mathbf{2 0 0 4 - 0 5}$ & $\mathbf{2 0 1 0 - 1 1 *}$ \\
\hline Cereals & 18.08 & 26.13 & 35.0 & 374 & 464 & 647 \\
\hline Potato & 1.50 & 5.95 & 8.30 & 32 & 108 & 153 \\
\hline Pulses & 0.53 & 0.31 & 0.72 & 11 & 10 & 13 \\
\hline Oilseed & 0.48 & 0.56 & 0.84 & 10 & 10 & 15 \\
\hline Vegetable & 1.21 & 6.50 & 11.19 & 21 & 108 & 207 \\
\hline Fruits & 1.41 & 4.60 & 3.56 & 24 & 68 & 65 \\
\hline Fish & 1.17 & 2.10 & 2.89 & 27 & 41 & 53 \\
\hline Meat & 0.48 & 1.06 & 1.90 & 11 & 21 & 35 \\
\hline Milk & 1.52 & 2.14 & 2.95 & 35 & 42 & 54.60 \\
\hline Egg (Million) & 2400 & 5623 & 6078 & $19 * *$ & $41^{* *}$ & 41 \\
\hline
\end{tabular}

Source: BBS 2011, DAE, DLS, DOF, BARC * Population 148.69 million in 2011, ** per year 


\section{Import}

For the sake of convenience, public import and food aid data are taken together for discussion as the volume is not large compared to domestic production and private import. Import of food grains either by the private sector or by the public sector does not follow any pattern (Table 5). It depends on the gaps in production created by flood damage or damage due to other natural disasters (of course, private sector import can be affected, if the Government imported stock is sold in the open market at a subsidized price). The total import (private and public), on average, is 3.13 million tons per year (estimation based on Table 5), with substantial increase in imports in years following poor harvests due to flood and drought or other natural disasters. Table 5 shows that with gradual increase of private sector import, public sector import of food grains has decreased. Public sector import is expected to level off with further increase of private sector import which is more likely to happen in the future. In the domain of import either by the Government or by the private sector, quality, price and timing of import are important parameters that need to be taken into account in ensuring food security.

No fixed trend is observed in public distribution and domestic procurement of food grains. In some years, both distribution and procurement of food grains increased and in other years, it decreased, probably it is due to demand flexibility. The domestic food procurement data gives a signal that the food procurement policy needs to be stream lined, based on production forecast, weather forecast, and in relation to import policy.

Table 5: Private import and public import of rice and wheat, public distribution and domestic procurement 2010-11

\begin{tabular}{|c|c|c|c|c|c|}
\hline Year & $\begin{array}{c}\text { Private Import } \\
\text { (Rice \& Wheat) }\end{array}$ & $\begin{array}{c}\text { Public Import + } \\
\text { Food Aid (Rice \& } \\
\text { Wheat) }\end{array}$ & $\begin{array}{c}\text { Total } \\
\text { Import }\end{array}$ & $\begin{array}{c}\text { Distribution } \\
\text { Public }\end{array}$ & $\begin{array}{c}\text { Domestic } \\
\text { Procurement }\end{array}$ \\
\hline $2001-02$ & 1.29 & 0.51 & 1.80 & 1.46 & 1.05 \\
\hline $2010-11$ & 2.08 & 1.05 & 3.13 & 2.73 & 1.60 \\
\hline
\end{tabular}

\section{Current availability and gaps:}

The total requirement of cereals in 2010-11 is estimated to be 23.64 million tons, based on 435.6 g/capita/day consumption (BBS Household Income and Expenditure Survey 2010) for a population size of 148.69 million. Against this, production of cereals (cleaned rice and wheat) in 2010-11 is estimated at 31.50 million tons after deduction of $10 \%$ for seeds, feed and wastage. Potato production is reported to be surplus by 6.25 million tons. Gaps between requirement and production of other important food crops and livestock products are wide. These gaps are likely to widen by 2015, if appropriate policy and development interventions are not taken with urgency. 
Table 5: Projected requirements and production of major food items in 2015

(Million MT)

\begin{tabular}{|l|l|l|l|l|}
\hline Food Items & $\begin{array}{l}\text { Food Production } \\
\text { in 2010-11 }(\mathbf{m T}) \\
(\mathbf{l e s s ~ 1 0 \% )}\end{array}$ & $\begin{array}{l}\text { Requirements in } \\
\mathbf{2 0 1 5}(\mathbf{m T}) \\
\mathbf{( l e s s ~ 1 0 \% )}\end{array}$ & $\begin{array}{l}\text { Production in } \\
\mathbf{2 0 1 5}(\mathbf{m T}) \\
(\mathbf{l e s s} \mathbf{1 0} \%)\end{array}$ & $\begin{array}{l}\text { Surplus (+) } \\
\text { Gaps (- }) \\
(\mathbf{m T})\end{array}$ \\
\hline Rice \& wheat & 31.5 & 25.29 & 35.00 & +9.71 \\
\hline Pulses & 0.65 & 2.32 & 0.97 & -1.35 \\
\hline Oilseeds & 0.76 & 1.28 & 0.90 & -0.38 \\
\hline Vegetables & 10.07 & 9.58 & 9.82 & -0.24 \\
\hline Fruits & 3.52 & 2.90 & 5.15 & -2.25 \\
\hline Potato & 7.47 & 3.48 & 10.00 & +6.52 \\
\hline Fish & 2.8 & 3.25 & 4.00 & +0.75 \\
\hline Meat & 1.71 & 0.98 & 2.45 & -1.47 \\
\hline Milk & 2.66 & 14.29 & 4.54 & -9.75 \\
\hline Egg (million) & 54702 & 16297 & 11052 & -5245 \\
\hline Source: BBS, DAE, BARC, DLS, DOF, Requirent food in 2015 calculated by population 159.07 million & & \\
\hline
\end{tabular}

\section{MEASURING FOOD SECURITY AND INSECURITY}

In order to understand better the nature and extent of the food security situation and the possible ways to improving it, it is important to distinguish between food security at the national, local, household and intra-household level. The ultimate goal is to meet the food requirements of the people at all levels.

Food security at the national level is determined by the availability of enough resources for the whole population. The most widely used indicators are quantities of available food compared with needs, as well as import requirements compared with the country's capacity to import.

At the sub-regional levels, food security can be measured by comparing regional nutritional requirements with availability of dietary calories per head. Furthermore, the problem is increasingly being used in terms of seasonal or local level.

At the household level, food security is dependent on a household's access to enough food. Thus it is closely linked with the issue of poverty, access, sufficiency, vulnerability and sustainability. At the household level, food security is measured by actual dietary intake of all household members using household income and expenditure surveys. It is important that changes in socio-economic and demographic variables be monitored continuously over time.

A food poverty indicator shows the number of individuals living in a household whose access to food is sufficient to provide a dietary intake adequate for growth, activity and good health. Individual food security implies an intake of food and absorption of nutrients sufficient to meet an individual's needs for activity, health, growth and development. The individual's age, gender, body size, health status and level of physical activity determine the level of need.

\section{IDENTIFYING THE FOOD INSECURE}

Food security at the national level is perhaps best described as a satisfactory balance between food demand and food supply at reasonable prices. Food security at national level, i.e., self-reliance in food at the national level does not necessarily mean food security at the household or individual level. 
It is important as a first step in developing an appropriate strategy for enhancing food security to identify the nature and level of food insecurity problems. Although some household problems can be tackled at the national level, and some national level problems will respond to an increase in household entitlements, the interaction between the different levels of food security are critical in devising an effective response. To visualize the role of the government in clear terms it is necessary to develop mechanisms to take background research and analytical exercises and disseminate results.

We have argued that food security at national level, i.e., self-reliance in food at the national level does not necessarily mean food security at the household or individual level. Thus overall production or availability of food grain may be a bad indicator of what the vulnerable groups in the population can actually acquire. Food may rank highest among basic human needs, but it will not be reflected in the market as long as it is not adequately backed up by purchasing power (effective demand).

Even when aggregate food supplies are adequate, a number of factors may prevent poor households or individuals from acquiring enough food. Income levels of the poor may be insufficient to enable them to purchase the necessary foods at the prices prevailing in the market.

These households may also lack the necessary assets or access to credit to help them get through difficult times. Moreover, they may find themselves outside any public assistance or other program that would provide them with transfers in-kind or as cash to supplement their food acquisition capacity.

Poverty and hunger, as we know, are not simply economic problems in the narrow sense, but more importantly it has social and political dimensions as well. Since the market does not care about the food security needs of the food deprived population, the government will have to play the caring role if the objective of ensuring food security of the citizens is to be achieved in Bangladesh because of so high incidence of absolute poverty.

\section{FOOD SECURITY AND GOVERNANCE}

Bangladesh agriculture has achieved significant structural changes over the past three and half decades. Despite many problems and constraints a quiet agricultural revolution has taken place which is still evolving in response to natural calamities, sociopolitical changes, population growth, and urbanization, new technology in agriculture and new opportunities in rural non-agriculture sector commercialization and changes in macro policy and sector intervention in agriculture. Improved national governance is most needed today to reduce hunger. Democracy is one useful standard of good governance. Bangladesh is at the cross-roads in its efforts to combat poverty and achieve food security for its people. The full Poverty Reduction Strategy has just been completed, recognizing that "food security is the core element in the struggle against poverty" (GED 2005) and setting out a number of policy priorities that will inevitably influence the availability, access and utilization of food. The National Food Policy has been approved. Whilst earlier five year plans emphasized accelerated food production and expansion of employment opportunities in rural areas as the main strategy to achieve food security, the new National Food Policy builds on a more comprehensive understanding of the food security challenge in Bangladesh which includes, in addition to availability, access and utilization considerations.

Internal peace: Governments in Bangladesh must do a better job of preserving internal peace. Where national governments fail to preserve internal peace, food production and access to food are compromised. Present government has the utmost priority on internal peace in Bangladesh 
Rule of law: The prosperity of Bangladesh agriculture is satisfactory because of good civil and judicial systems or arbitrary and anti-corrupt governmental administration has tended to encourage private investment.

Public investment in rural infrastructure: Such investments are moderate strong in Bangladesh, increasing the life chances of the rural poor. More than 49.8 percent of rural people in the poorest income quintile live in rural settings, and very few of these poor rural households enjoy the basic infrastructure needed for a healthy and productive life.

Government support for agricultural research and development: Between 1971 and 2011, public spending on agricultural research and development in Bangladesh is increased. One percent of AGDP is allocated for agricultural research is planned in future. Strong coordinated efforts by both the public and the private sectors, non-governmental and community based organizations will be needed to increase food production for achieving the millennium development targets. This would require stronger GO-NGO private sector partnership, with effective coordination and monitoring system in place at both the national and local levels.

\section{CHALLENGE FOR FOOD SECURITY AND GOOD GOVERNANCE}

\section{Technical problems}

Some of the persisting problems of increasing crop production, particularly cereal production using the available HYVs are decreasing soil productivity, inefficient water and fertilizer use, inadequate supply of quality seeds, imbalanced use of fertilizer, low labour productivity, and higher input price. These factors are restricting realization of full yield potential of HYVs, resulting in lower yield of cereals in the farmers' field compared with much higher yield obtained in the research station. The major concern is how to reduce this yield gap by improving soil, water and labour productivity, optimizing fertilizer use and reducing input price. Declining land resources and competing demand for limited land is a major concern for future agriculture. New technological breakthrough, appropriate development interventions and a robust land use policy will be needed to address the problems.

Smallholder dairy and poultry development, which has the highest potential for reduction of rural poverty, is seriously affected due to acute shortage of feeds and veterinary services, including disease diagnostic facilities. High price of feeds and chicks, and marketing of milk in the rural areas are also limiting progress in this area. One of the critical constraints limiting development of livestock is the absolute lack of quality control. In the absence of legal and regulatory framework, livestock development in the private sector is taking place in an indiscriminate manner, which has already created serious problems of quality control in livestock products, drugs, vaccines, feeds, and breeding materials. The main problems of fisheries subsector is the internal and trans-boundary environmental degradation and manmade hazards. In recent years, complaints are heard about the degrading quality of fingerlings (not genetically true to types) affecting pond fisheries, and disease infestation in shrimp culture. Destruction of fish breeding grounds is also a major problem restricting production of native fish species. Despite the declining quality of fingerlings, pond aquaculture is reported to have reached the optimal level of production. The major challenge of the sub-sector is to harness the huge potential of inland open water fisheries.

\section{Institutional problems}

Institutional capacity of the research, extension and seed production systems in terms of facilities and human and financial resources has weakened and are not geared to address the emerging problems. 
Weaknesses also persist in planning, coordination, monitoring, inter-institutional linkages, resource management and partnership with the private sector and NGOs. These problems are overwhelming in the livestock sub-sector compared to crops. DLS still continues to provide some of the services that can be better done by the private sector. They are doing very little in quality assurance, disease investigation and surveillance, and veterinary public health. Institutional reform is long overdue to tune up the systems and build the capacity to face the new challenges.

Institutional capacity of the Ministry of Food and Disaster Management in assessing, planning, monitoring and implementing the policy and development interventions to effectively deal with the food security issues is relatively weak due to shortage of skilled manpower. The capacity of the Food Policy and Monitoring Unit (FPMU) in terms of professional strength and skill mix is also weak. Inter-ministerial coordination and interaction on food security, research capacity and the process of having regular dialogue with the private sector and civil society are lacking. There is a need to develop the planning, coordination and monitoring capacity of the Ministry, and improving inter-ministerial interaction to deal with the food security issues related to production, access and utilization.

\section{Funding}

Investment in agriculture (crops, fisheries and livestock), in general, has been drastically reduced from last three decades. ADP share has also declined from 45\% in 1981-82 to less than $10 \%$ in $2010-11$. Donor funding in agriculture has also declined significantly, although one of the conditions for attaining MDG is the commitment of extended donor support in agriculture. Livestock sub-sector is affected most due to low budget allocation. Annual revenue allocation to the Department of Livestock Services has declined from $0.57 \%$ of the annual national budget in 1997-98 to $0.38 \%$ in $2003-04$ (Bangladesh Economic Review 2010). Funding situation in fisheries is slightly better. It is noted that the investment in agricultural research for generation of technology is very minimum, which only $0.32 \%$ of total AGDP. Investment should be raised upto 1\% to develop adequate research facilities as per need of the nation. However, without substantial increase in budget allocation to agriculture, it will be next to impossible to attain the production target projected for the year 2015 to meet the millennium development goals.

\section{RECOMMENDATIONS}

1. Expansion of community based nutrition programme should be considered with utmost importance

2. Targeted safety net programmes for the poor and ultra poor should be continued and made more effective

3. Supports should be expanded for income generating activities for the rural poor

4. Supports should be continued for the marginal farmers to enhance agricultural production

5. Community based health and nutrition education should be strengthened

6. Proper enforcement of laws and regulation related to food safety and quality should be ensured

7. Food standards as well as standards for inspection, testing, labeling, packaging should be harmonized with that of international standards

8. Monitoring and surveillance of food products in the market should be strengthened

9. NPAN should be reviewed and updated with the recent developments

10. Transferring knowledge about balanced diet and its usefulness to the household, especially to the mother 
11. Incorporation of calorie intake and other issues in the text books at school level

12. Focus agricultural research on dietary quality (research on non-cereal crops)

13. Food price policy for increasing the quality and quantity of food

14. Supportive policies for agriculture input

15. Commercial and homestead promotion of poultry and fruits/vegetables

16. Addressing growing income inequality and effective and equitable social interventions

17. Looking into intra-household discrimination in food allocation.

\section{CONCLUSIONS}

All policy documents on crops, livestock, fisheries and food are recently prepared in the context of changes in global and domestic social, economic and trade environment. The policies are sound, but if they are not implemented in totality, it will not be possible to achieve the food production target estimated for the year 2015. In the past, it was seen that the policies that require fundamental changes like institutional reform were always bypassed. As a result, only partial success was achieved. Achieving the millennium development target will rest on the following conditions: (i) substantial increase in public and private investment, (ii) institutional and management reform, (iii) close interinstitutional and inter-ministerial cooperation, (iv) GO-NGO-private sector partnership, (v) good agricultural governance, particularly at the local level, and (vi) commitment of the Government. The implication is that a twin-track strategy is needed in Bangladesh, tackling food insecurity from two angles: I) sustainable agricultural and rural development to support and enhance the livelihoods of the poor and vulnerable groups; and II) through targeted interventions and programmes to enhance immediate and direct access to food and nutrition by the most needy to allow them to take advantage of opportunities offered by development.

\section{REFERENCES}

BARC (Bangladesh Agricultural Research Council).2011. Research Priorities in Bangladesh Agriculture, Agriculture Research Vision 2030 and Beyond. p-20.

BER (Bangladesh Economic Review). 2010. Department of Finance, Ministry of Finance. Bangladesh. pp.83-85.

Government of Bangladesh. 2005. Unlocking the Potential: National Strategy for Accelerated Poverty Reduction. General Economics Division (GED), Bangladesh.

Hossain, 2004. Food Security and Nutrition in Bangladesh: Progress and Determinants, a report prepared for FAO, Rome.

Position Paper on Food Security in Bangladesh 2005, Ministry of Agriculture.

Position Paper on Food Security in Bangladesh (Livestock) 2005, Department of Livestock Services, Ministry of Fisheries and Livestock.

Position Paper on Food Security in Bangladesh (Fisheries) 2005, Department of Fisheries, Ministry of Fisheries and Livestock.

UNDP, 2005. Government of Bangladesh- United Nation, Millennium Development Goal Report, United Nation Development Programme. 